\title{
Selection of Reference Genes for Real-time Quantitative PCR Normalization in the Process of Gaeumannomyces graminis var. tritici Infecting Wheat
}

\author{
Li-hua Xie ${ }^{1 \dagger}$, Xin Quan ${ }^{1 \dagger}$, Jie Zhang, Yan-yan Yang ${ }^{1}$, Run-hong Sun ${ }^{1}$, Ming-cong Xia ${ }^{1}$, Bao-guo Xue ${ }^{1}$, \\ Chao $\mathrm{Wu}^{1}$, Xiao-yun Han ${ }^{1}$, Ya-nan $\mathrm{Xue}^{2}$, and Li-rong Yang ${ }^{10}{ }^{1 *}$ \\ ${ }^{l}$ Institute of Plant Protection Research, Henan Academy of Agricultural Sciences, Henan Key Laboratory for Control \\ of Crop Diseases and Insect Pests, IPM Key Laboratory in Southern Part of North China for Ministry of Agriculture, \\ Zhengzhou, Henan 450002, P. R. China \\ ${ }^{2}$ Agricultural and Animal Husbandry Bureau of Mianchi, Sanmenxia 472400, P.R. China
}

(Received on March 22, 2018; Revised on September 30, 2018; Accepted on October 4, 2018)

Gaeumannomyces graminis var. tritici is a soil borne pathogenic fungus associated with wheat roots. The accurate quantification of gene expression during the process of infection might be helpful to understand the pathogenic molecular mechanism. However, this method requires suitable reference genes for transcript normalization. In this study, nine candidate reference genes were chosen, and the specificity of the primers were investigated by melting curves of PCR products. The expression stability of these nine candidates was determined with three programs-geNorm, Norm Finder, and Best Keeper. TUB $\beta$ was identified as the most stable reference gene. Furthermore, the exopolygalacturonase gene $(E x o P G)$ was selected to verify the reliability of $T U B \beta$ expression. The expression profile of ExoPG assessed using TUB $\beta$ agreed with the results of digital gene expression analysis by RNA-Seq. This study is the first systematic exploration of the optimal reference genes in the infection process of Gaeumannomyces graminis var. tritici.

\footnotetext{
${ }^{\dagger}$ These authors contributed equally to this work as first authors. *Corresponding author.

Phone) \& FAX) 0086-371-65852150

E-mail) luck_ylr@126.com

ORCID

Li-rong Yang

https://orcid.org/0000-0002-8270-3214

(c) This is an Open Access article distributed under the terms of the Creative Commons Attribution Non-Commercial License (http:// creativecommons.org/licenses/by-nc/4.0) which permits unrestricted noncommercial use, distribution, and reproduction in any medium, provided the original work is properly cited.
}

Articles can be freely viewed online at www.ppjonline.org.
Keywords : geNorm, housekeeping gene, Triticum aestivum, TUB $\beta$

Handling Editor : Kim, Ki Woo

Gaeumannomyces graminis var. tritici $(G g t)$, a soilborne pathogenic fungi of wheat roots, causes "take-all disease" on roots of wheat and other cereals and results in severe crop losses worldwide. Take-all disease is an area of intense current interest of research on wheat root diseases yet remains the most important root disease of wheat worldwide. The genetic improvement of resistance in wheat to this pathogen remains a priority, and the study of pathogenic gene expression patterns is crucial for understanding the molecular mechanisms underlying the infection process, providing valuable information for wheat resistance breeding programs.

According to our previous RNA-Seq analysis (Yang et al., 2015), 3,258 DEGs (2,107 up-regulated genes and 1,151 down-regulated genes) were detected during infection process of Ggt. Hence these candidate genes were presumed to play important role in infection process. However, how these genes regulate infection process is still unclear. The more accurate and precise expression pattern of every candidate gene would be helpful to understand how it plays a crucial part. RT-qPCR has become a powerful and frequently used experimental method to evaluate gene expression levels due to its high sensitivity, specificity, accuracy, and reproducibility (Bustin, 2002; Bustin et al., 2005; Nolan et al., 2006). Furthermore, in some cases, it is the only method that allows for the detection of low copy numbers of genes of interest and slight variations in gene expression (Bustin, 2010). Regardless of its many advantages, 
this method requires appropriate reference genes to ensure the reliability of the target gene's expression. Recent studies have shown that no single reference gene is universally applicable for all systems. Those genes (e.g., 18S $r R N A$, actin, tubulin, et al.) involved in basic cellular processes have been frequently used as reference genes. However, many studies have demonstrated that some of these reference genes might not be stably expressed under some conditions (Gutierrez et al., 2008; Schmittgen et al., 2000). For example, Gapdh, which is typically used as reference gene, shows the lowest expression stability among different Aspergillus niger AB1.13 culture conditions (Bohle et al., 2007). Similarly, the research of Kim and Yun (2011) found that $G A P D H$ is an unsuitable reference gene, while $\mathrm{Gz} U B H$ and $E F 1 A$ are most stable reference gene of $F u$ sarium graminearum $\mathrm{PH}-1$ strain under different culture conditions. In rust-infected wheat, ADP-ribosylation factor and RNase L inhibitor-like protein (RLI) encoding genes showed the best stability in Puccinia Striticina-infected wheat, while the cell division control (CDC) protein and RLI encoding genes showed the best stability in Puccinia Striiformis-infected wheat (Scholtz and Visser, 2013). However, in Puccinia graminis f.sp. tritici-infected wheat, $C D C, 18 S$ rRNA, and $\beta$-Tubulin showed the best stability. Thus, a credible reference gene should be evaluated before performing RT-qPCR studies. Many studies have addressed the selection of reference genes in plants and fungi, but none have done so in Ggt, a harmful fungus. This study was conducted to identify reference genes for transcript normalization of pathogenic genes during the infecting process of Ggt. The expression profiles of nine reference genes including GAPDH (Glyceraldehyde-3-phosphate dehydrogenase), TUB2 (tubulin alpha chain), G6PDH (Glucose6-phosphate-1-dehydrogenase), $G K$ (Glucokinase), $E F-3$ (Elongation factor 3), EF2-2 (Elongation factor 2), $T U B \beta$ (Tubulin beta), $A C T$ (Actin) and EF2-1 (Elongation factor) were studied in different stages of $G g t$-infected wheat, and the expression stability of these genes was evaluated with geNorm (Vandesompele et al., 2002), NormFinder (Andersen et al., 2004) and Bestkeeper (Pfaffl et al., 2004). Furthermore, the expression pattern of target gene ExoPG (exopolygalacturonase) was investigated using the selected reference gene, which may be helpful in revealing its role in Ggt pathogenicity.

\section{Materials and Methods}

Fungal meterials and infection of wheat roots. An isolate of Ggt (GGT-007, Henan Academy of Agricultural Sciences, Zhengzhou, China) was isolated by Quan et al.
(2014). Liquid cultures were grown in potato dextrose broth at $25^{\circ} \mathrm{C}$ with shaking at $180 \mathrm{rpm}$ for $5 \mathrm{~d}$ to prepare for wheat root infection and Ggt RNA extraction.

Seeds of winter wheat (Aestivumtriticum cv 'Zhengmai 366') were supplied by the Wheat Research Institute of the Henna Academy of Agricultural Science. The experiment of accelerating germination and inoculation procedure of wheat root were carried out according to Yang et al. (2015a). The wheat roots infected by Ggt samples from three biological replicates were collected at $0.5,1,2,3,4$, $5,7 \mathrm{~d}$ after inoculation. The liquid culture of $G g t$ was control group. The samples were immediately frozen and then stored in liquid nitrogen until analysis.

Extraction of total RNA and synthesis of cDNA. Frozen Ggt hypha and infected-wheat roots were ground to a fine powder in liquid nitrogen with a pestle and mortar. About $100 \mathrm{mg}$ of powder was used for RNA extraction. Total RNA was isolated using the RNAiso Plus (TaKaRa, Dalian, China). Purified RNA was quantified with NanoDrop2000 spectrophotometer (Thermo, Wilmington, DE, USA), and the concentration and integrity of RNA was checked by a denaturing $1.0 \%(\mathrm{p} / \mathrm{v})$ agarose gel. Only RNA samples with $260 / 280$ wavelength ratio between 1.9 and 2.1 were used for cDNA synthesis. cDNA was synthesized with $1 \mu \mathrm{g}$ total RNA according the manufacturer of the Prime Script ${ }^{\mathrm{TM}}$ RT reagent Kit with gDNA Eraser (Perfect Real Time) (TaKaRa, Dalian, China) in a total volume of $20 \mu \mathrm{l}$ cDNA was stored at $-20^{\circ} \mathrm{C}$.

Primer design and PCR conditions. The nine candidate reference genes (PFK, GAPDH, TUB2, G6PDH, GK, EF3, EF2-2, TUB $\beta, A C T$ and $E F 2-1)$ and one target gene ExoPG were selected from Transcriptome Sequencing Data and Genebank. Their accession numbers are listed in Table 1. Primer sequences were designed using Primer 3.0 (primer3.ut.ee/) with the following parameters: Tm around $60^{\circ} \mathrm{C}$ and product size ranges $150-250$ base pairs, primer sequences with a length of 18 to 22 nucleotides, and a GC content of $45-55 \%$. All the primers' specificities were confirmed using Primer-BLAST searches on $\mathrm{nr}$ database of NCBI and analyzed by real-time PCR and electrophoresis on $2 \%$ agarose gel.

QRT-PCR reactions were performed in 96-well plates with Step One Plus Real-Time PCR System (Applied Biosystems, CA, USA) and a $\mathrm{SYBR}^{\circledR}$ Premix Ex Taq ${ }^{\mathrm{TM}} \mathrm{Kit}$ (TaKaRa, Tokyo, Japan). The qRT-PCR conditions were as follows: $95^{\circ} \mathrm{C}$ for $30 \mathrm{~s}$ and 40 cycles of $95^{\circ} \mathrm{C}$ for $5 \mathrm{~s}$ and $60^{\circ} \mathrm{C}$ for $30 \mathrm{~s}$. The amplicons specificities were detected by melting curves analysis $\left(60\right.$ to $\left.95^{\circ} \mathrm{C}\right)$ after 40 PCR cycles. 
Analysis of candidate reference gene expression stability. For every primer pair, a standard curve was used to calculate the gene-specific PCR efficiency from the 5-fold series dilution of Ggt cDNA. The correlation coefficients $\left(\mathrm{R}^{2}\right)$ and slope value were determined from the standard curve. The following formula was used to calculate the qRT-PCR efficiencies (E). $\mathrm{E}=\left(5^{-1 / \text { slope }}-1\right) \times 100$ (Radonić et al., 2004).

The expression stabilities of all the candidate genes were evaluated by three Excel-based softwares: geNorm (Vandesompele et al., 2002), BestKeeper (Andersen et al., 2004), and NormFinder (Pfaffl et al., 2004). The geNorm (http://medgen.ugent.be/ jvdesomp/genorm/) is based on the mean pairwise variation between all the tested genes to calculate the expression stability value (M) of genes, and BestKeeper (http://www.gene-quantification.de/bestkeeper. $\mathrm{html}$ ) is used to evaluate the expression stability according to an index which is obtained by standard deviation (SD) and percentage covariance (CV). NormFinder (http:// www.mdl.dk/publicationsnormfinder.htm) is used to rank the genes expression stability according to their intra- and inter-expression variation.

\section{Results}

Identification of reference gene candidates and primer specificity and efficiency. Nine reference gene were selected for RT-qPCR normalization. Gene name, accession number, gene description, primer sequences, melting temperatures value $\left(\mathrm{T}_{\mathrm{m}}\right)$, amplification efficiency and correlation coefficients are listed in Table 1 . The Tm of PCR products ranged from $86.2^{\circ} \mathrm{C}$ for $E F-3$ to $89.63^{\circ} \mathrm{C}$ for $G A P D H$. Amplification efficiency (E) of PCR reactions ranged from 103.7 for $G A P D H$ to 119.82 for $E F-3$. Correlation coefficients $\left(\mathrm{R}^{2}\right)$ ranged from 0.9853 for TUB2 to 0.9999 for EF-3. The amplifications were confirmed by the presence of a single band in $1.5 \%$ agarose gel electrophoresis and by the single peak melting curve of the PCR products (Fig. 1A, B), and the size of PCR products were consistent with expected size for each primer pairs.

Expression levels of the selected candidate reference genes. Based on average cycle threshold $(\mathrm{Ct})$ values, there were obvious differences in transcript levels among the reference genes during Ggt infection. The $\mathrm{Ct}$ range and coeffi-

Table 1. Candidate reference genes, primers and different parameters derived from RT-qPCR

\begin{tabular}{|c|c|c|c|c|c|c|}
\hline $\begin{array}{l}\text { Gene } \\
\text { symbol }\end{array}$ & $\begin{array}{l}\text { Accession } \\
\text { number }\end{array}$ & Gene description & $\begin{array}{l}\left.\text { Primer pair ( } 5^{\prime} \text { to } 3^{\prime}\right) \\
\text { (forward/reverse) }\end{array}$ & $\begin{array}{l}\mathrm{T}_{\mathrm{m}} \\
\left({ }^{\circ} \mathrm{C}\right)\end{array}$ & $\begin{array}{l}\text { Amplification } \\
\text { efficiency }(\%)\end{array}$ & $R^{2}$ \\
\hline GAPDH & XM_009222105 & $\begin{array}{l}\text { Glyceraldehyde-3- } \\
\text { phosphate dehydrogenase }\end{array}$ & $\begin{array}{l}\text { CGTGATGGGTGTCAACGAGA/ } \\
\text { GCTGCTGGGGATGATGTTCT }\end{array}$ & 89.63 & 103.7 & 0.9954 \\
\hline$T U B 2$ & XM_009228181 & tubulin alpha chain & $\begin{array}{l}\text { GCCGTTTCTCGGGTCACAG/ } \\
\text { CAACCGTCTCATTGCTCAG }\end{array}$ & 86.8 & 105.73 & 0.9853 \\
\hline$G 6 P D H$ & XM_009230131 & $\begin{array}{l}\text { Glucose-6-phosphate1- } \\
\text { dehydrogenase }\end{array}$ & $\begin{array}{l}\text { GTCGGGCATCTTCAAGGACA/ } \\
\text { TCGTCTCGCACAAAGTTGGA }\end{array}$ & 88.59 & 104.02 & 0.997 \\
\hline$G K$ & XM_009229629 & Glucokinase & $\begin{array}{l}\text { CTTGAACACGGGCGTCAAAG/ } \\
\text { ACACCCTGAAGTTAGTGCCG }\end{array}$ & 86.8 & 114.42 & 0.9989 \\
\hline$E F-3$ & XM_009221076 & Elongation factor 3 & $\begin{array}{l}\text { GGAGGCCAAGGTTGATGTCA/ } \\
\text { AGCAGCAGAATATCGGGAGC }\end{array}$ & 86.2 & 119.82 & 0.9999 \\
\hline$E F 2-2$ & XM_009220540 & Elongation factor 2 & $\begin{array}{l}\text { TGTCGACCGCAACAAGATGA/ } \\
\text { TTGCCCTCCTTGTCCTTGTC }\end{array}$ & 87.39 & 102.97 & 0.9961 \\
\hline$T U B \beta$ & XM_009231745 & Tubulin beta & $\begin{array}{l}\text { TCCCAACAACATCCAGACCG/ } \\
\text { TCCATACCCTCGCCAGTGTA }\end{array}$ & 86.35 & 105.32 & 0.9974 \\
\hline$A C T$ & XM_009225830 & Actin & $\begin{array}{l}\text { GTGACGAACTGGGACGACAT/ } \\
\text { GGCGTTGAAGGTCTCGAAGA }\end{array}$ & 88.74 & 110.36 & 0.9974 \\
\hline$E F 2-1$ & XM_009218808 & Elongation factor & $\begin{array}{l}\text { CATCAAGCGCATGTCTTCCG/ } \\
\text { GGTCGACCGTGTTCTTCCAT }\end{array}$ & 89.04 & 111.81 & 0.9975 \\
\hline ExoGP & XM_009227044 & Exopolygalacturonase & $\begin{array}{l}\text { TCGACGACTTTCAGCTGCAC/ } \\
\text { CCGGCAAACTCATTCCACCA }\end{array}$ & 87.25 & 102.90 & 0.9965 \\
\hline
\end{tabular}



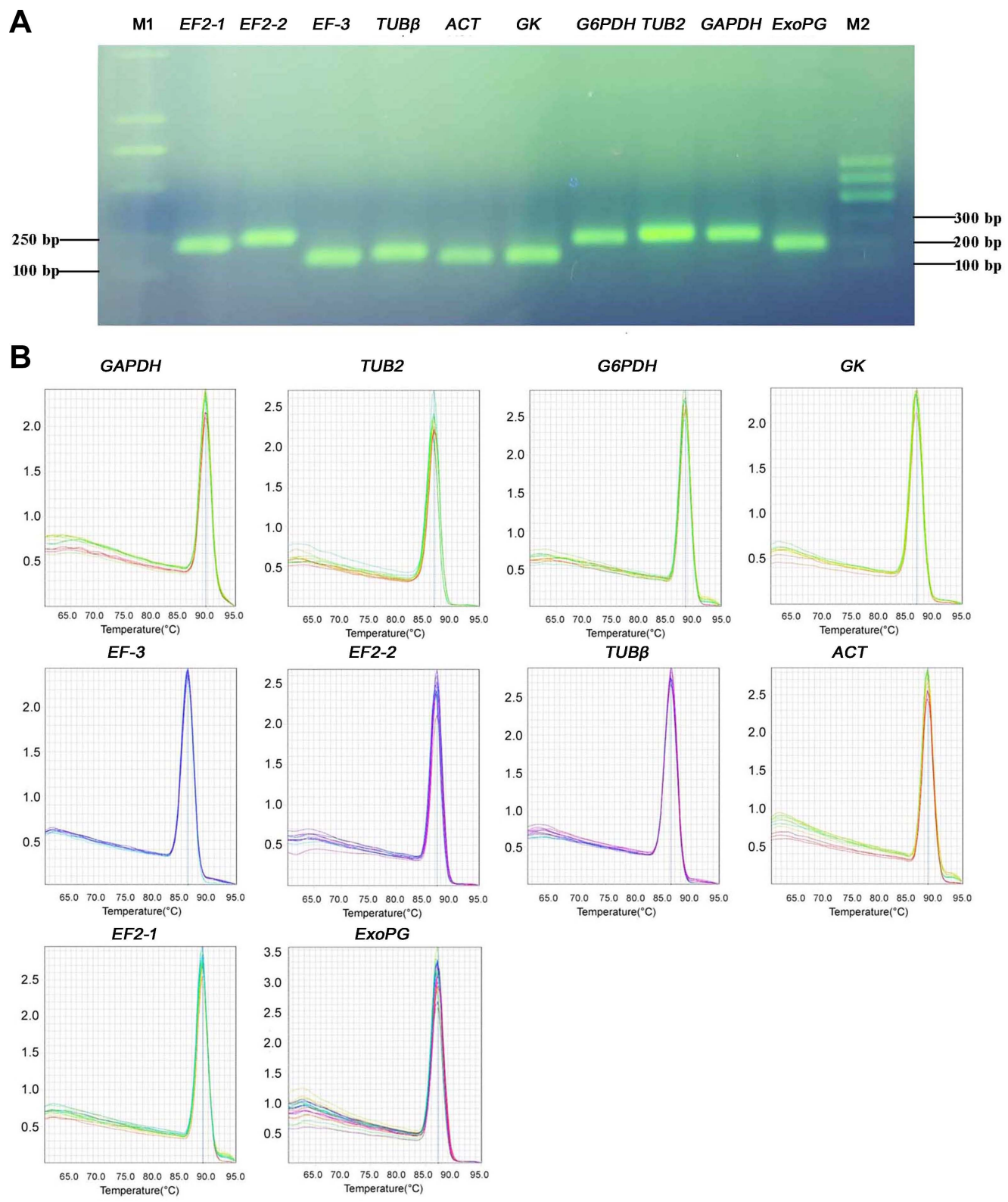

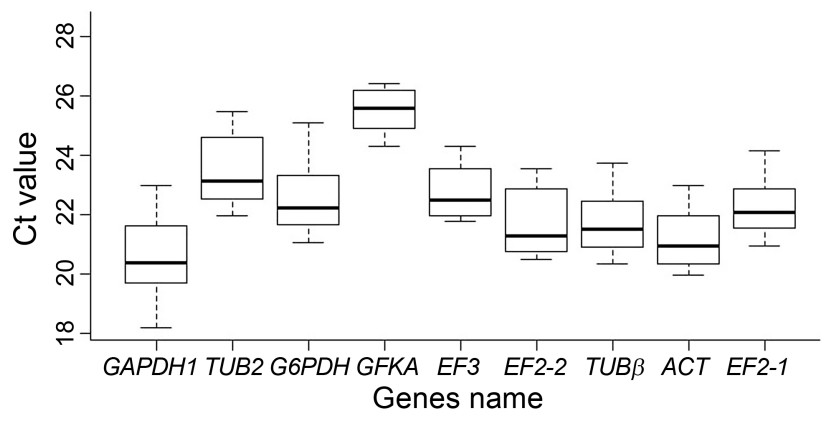

Fig. 2. RT-qPCR Ct values for reference genes. Expression data displayed as $\mathrm{Ct}$ values for each reference gene in all Ggt and Ggtinfected wheat root samples. A line across the box is depicted as the median. The box indicates the 25 th and 75 th percentiles, whiskers represent the maximum and minimum values.
Fig. 1. Specificity of RTqPCR and amplicon size. (a) Agarose gel (1.5\%) electrophoresis showing amplification of a specific PCR product of the expected size for each gene. (b) Melting curves of one target gene and nine reference genes showing single peaks. M1 and M2 represent D2000 DNA Marker (150 bp-2000 bp) and DNA Marker I (100 bp-600 bp) marker, respectively.

cient of variance for each gene were also obtained from the $\mathrm{Ct}$ value. As expected, the average $\mathrm{Ct}$ values varied from 20.56 for $G A P D H$ to 25.77 cycles for $G K$ (Fig. 2). Most of them were expressed abundantly (ranging from 20 to 25 ). Among them, GAPDH was the most abundantly expressed reference gene, while GK was the least abundant. According to the coefficient of variance $(\mathrm{CV})$, which can reveal the reference gene's expression stability, $E F-3$ had the least variation with a $\mathrm{CV}$ value of $4.17 \%$, while GAPDH had the most variation with a $\mathrm{CV}$ value of $7.43 \%$.

Expression stability of candidate reference genes. $\mathrm{Ct}$ data were obtained from qRT-PCR. Ct values were used directly for stability calculations for BestKeeper, while $\mathrm{Ct}$ 

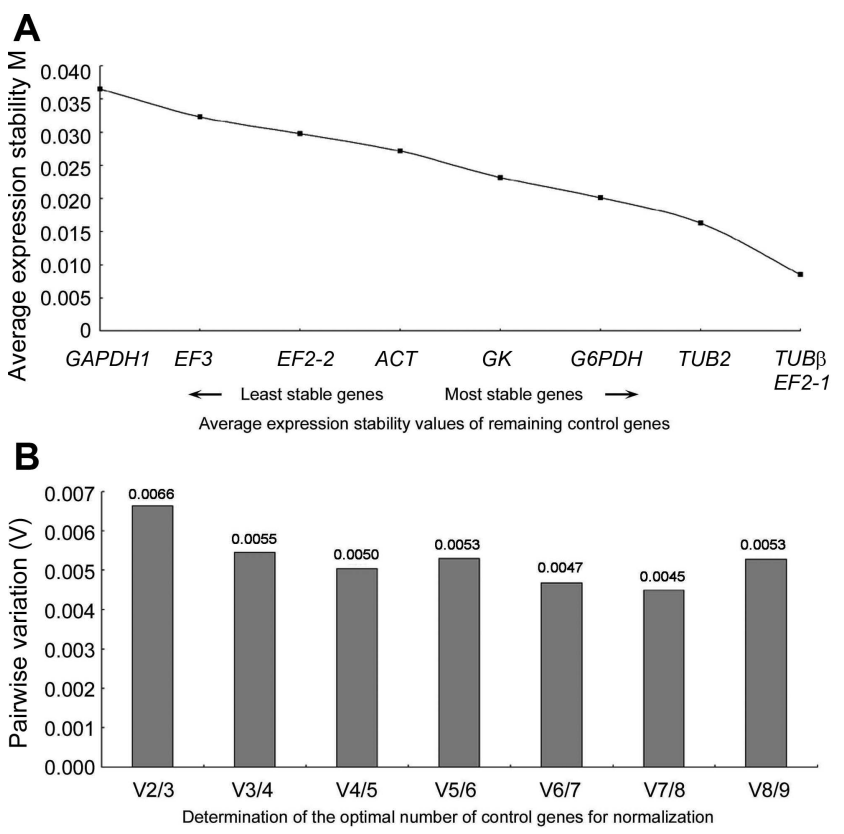

Fig. 3. Average expression stability values $(\mathrm{M})$ and Pairwise variation (V) calculated by geNorm to determine the optimal number of reference genes. The average pairwise variations $\mathrm{Vn} / \mathrm{Vn}+1$ was analyzed between the normalization factors NFn and NFn+1 to indicate the optimal number of reference genes required for RT-qPCR data normalization in different samples.

values were converted to relative quantities for geNorm and NormFinder.

Gene expression stability has a negative correlation with its $M$ value. It was calculated by geNorm software based on the average pairwise variation between all the tested reference genes. The most stable reference gene has the lowest $\mathrm{M}$ value. According the Fig. 3A, all the reference genes can be recognized as stable because they all had an $M$ value less than the geNorm threshold of 1.5. During the process of pathogen infections of wheat roots, $T U B \beta$ and $E F-2$ had the highest expression stability (i.e., the lowest $M$ values, 0.028 and 0.03 ), whereas GAPDH had the lowest stability $(\mathrm{M}$ value $=0.051)$. The other six genes were in between.

To select the optimal number of reference genes for credible normalization, pairwise variation $\left(\mathrm{V}_{\mathrm{n}} / \mathrm{V}_{\mathrm{n}+1}\right)$ between two sequential normalization factors $\mathrm{NF}_{\mathrm{n}}$ and $\mathrm{NF}_{\mathrm{n}+1}$ was calculated by geNorm (Fig. 3B). The result showed all pairwise variation to be smaller than the recommended threshold (0.15). Therefore, one reference genes would be sufficient for proper gene expression normalization throughout the infecting period.

NormFinder, an Excel-based software tool, evaluates the most stable reference genes according to the stability value
Table 2. Ranking of candidate reference genes in order of their expression stability as calculated by Norm Finder

\begin{tabular}{ccc}
\hline Rank & Gene & Stability value \\
\hline 1 & $T U B \beta$ & 0.004 \\
2 & $E F 2-1$ & 0.009 \\
2 & $T U B 2$ & 0.009 \\
3 & $G 6 P D H$ & 0.013 \\
4 & $A C T$ & 0.018 \\
5 & $E F 2-2$ & 0.02 \\
6 & $G F K A$ & 0.021 \\
7 & $E F 3$ & 0.027 \\
8 & $G A P D H 1$ & 0.032 \\
\hline
\end{tabular}

Table 3. Statistics results by Best Keeper software for ten selected genes based on $\mathrm{Ct}$ values

\begin{tabular}{ccccc}
\hline Rank & Gene & $\begin{array}{c}\text { Coeff. of } \\
\text { correlation }\end{array}$ & $P$-value & $\begin{array}{c}\text { Coeff. of } \\
\text { variation }\end{array}$ \\
\hline 1 & $T U B \beta$ & 0.991 & 0.001 & 4.00 \\
2 & $T U B 2$ & 0.984 & 0.001 & 4.45 \\
3 & $E F 2-1$ & 0.983 & 0.001 & 3.47 \\
4 & $G 6 P D H$ & 0.98 & 0.001 & 4.45 \\
5 & $G A P D H$ & 0.961 & 0.001 & 5.51 \\
6 & $A C T$ & 0.95 & 0.001 & 3.98 \\
7 & $E F 2-2$ & 0.943 & 0.001 & 4.72 \\
$\mathrm{~g}$ & $G K$ & 0.927 & 0.001 & 3.54 \\
9 & $E F 3$ & 0.891 & 0.003 & 3.43 \\
\hline
\end{tabular}

based on their intra- and inter-expression variation. Those with lower average stability values are regarded as more stable expression genes (Table 2). $T U B \beta$ was regarded as the most stable reference gene.

BestKeeper is used to rank the candidate genes based on their coefficient of correlation ( $r$ ) relative to the BestKeeper index, by calculating the $\mathrm{Ct}$ set standard deviation (SD) and coefficient of variance $(\mathrm{CV})$. The results (Table 3 ) revealed the best correlations were obtained for $T U B \beta(0.991)$ with the $P$ value of 0.001 , while the lowest correlations were obtained for $E F 3(0.891)$, with a $P$ value of 0.003 . Therefore, $T U B \beta$ was ranked as the most stable reference gene, which was in accordance with the results obtained from geNorm and NormFinder. In general, the results of Best Keeper analysis showed few differences from those obtained from geNorm and Normfinder.

Validation of the selected reference gene. To verify the reliability of the selected reference gene, we analyzed the expression pattern of one different expression transcript GGTG_09200 obtained from transcriptome sequencing. Transcript GGTG_09200 code ExoPG belongs to a group 


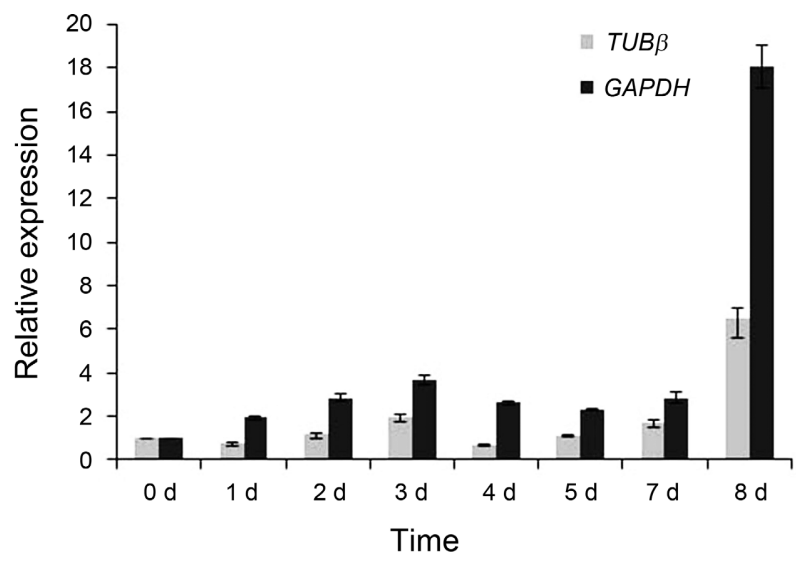

Fig. 4. The expression quantification of ExoGP normalized by $T U B \beta$ and $G A P D H$ as internal controls, respectively. Error bars represent standard error of the mean.

of plant cell wall degrading enzymes (PCWDEs), which can damage plant tissue, cell walls and cause leaks of cytoplasm (Kang et al., 2000; Valette-Collet et al., 2003).

The most appropriate reference gene $(T U B \beta)$ and the most inappropriate reference gene $(G A P D H)$ were selected for qRT-PCR normalization of ExoPG, respectively. ExoPG is important in the infection process of plant pathogenic fungi, and it might be activated to degrade pectin and hemicellulose to obtain nutrients or to weaken the wall to allow hyphal growth in the root. The normalization of qRT-PCR using $T U B \beta$ generated similar expression patterns with a low expression in earlier stages of infection process and the increase seven days after infection (Fig. 4), which agrees with the results of transcriptome sequencing. When the least stable reference gene $G A P D H$ was used for normalization, the ExoPG gene was expressed at high levels at the beginning of infection.

\section{Discussion}

At present, qRT-PCR has significantly improved the detection and quantification of expression profiles of genes of interest due to its high throughput, specificity, and accuracy (Bustin, 2002; Nolan and Bustin, 2006). However, it is important to select appropriate reference genes for gene expression normalization because of the relative expression of target genes can be influenced obviously by reference genes selected. Some commonly used reference genes have come under scrutiny or were doubted in recent studies for their variable expressions when tested with different experimental treatments (Ana et al., 2011; Fang et al., 2006; Hacquard et al., 2011; Huang et al., 2012; Teste et al., 2009; Yan and Liu, 2006).
Root and crown rot of wheat, also called "Take-all", and caused by fungus $G g t$, affects the quality and yield of wheat and other Gramineae crops. We might effectively improve the disease resistance of wheat through genetic improvement by understanding its intrinsic characteristic essentially of pathogenic (rewrite whole sentence). While up to now, the pathogenesis is unclear. Taking advantage of transcriptome data (Yang et al., 2015), a precious sequence resource for non-model fungus, and many pathogenicity-related genes will be identified with comprehensive functional analysis in the near future. In this study, we performed a selection and validation of internal reference genes for further accurate gene expression analysis using RT-qPCR in in the infection process of Ggt.

Although some previous studies have successfully used one or two of the three excel-based program geNorm, NormFinder and BestKeeper to select reference genes (Ana et al., 2011; Huang et al., 2012), we suggest that taking into consideration the stability ranking of all three programs would provide a certain degree of confirmation of the results. Although there were differences in the rank of the candidate reference genes according to the three programs, all three analytical programs used in this study found $T U B \beta$ to be the most stably expressed reference gene in the infection process of Ggt. ACT is a commonly used housekeeper gene for RT-qPCR expression normalization in fungi, however, it was found to be a relatively unstable reference gene in this study. This finding is consistent with the results of Ana et al. (2011) and Huang et al. (2012). Moreover, TUB $\beta$ is regarded as the least stable reference gene during the infection process of Hemileia vastatrix isolate 1065 (Vieira et al., 2011). In contrast, $T U B \beta$ was regarded as the most stably expressed reference gene during the infection processes of Ggt in our study. And the results of Yan and Liu (2006) and Huang et al. (2012) all show TUB $\beta$ is the most stably expressed housekeeper gene in infection processes of Phytophthora parasitica and Puccinia Striiformis f. sp. tritic, which might provide more accurate expression measurement of target genes.

In the infection progress of fungi, Phytopathogenic fungi expose plant cell walls to cell wall degrading enzymes (CWDEs), CWDEs like ExoPGs are needed for initial penetration and believed to be important pathogenicity factors (D'Ovidio et al., 2004; ten Have et al., 1998; Weste, 1970). To validate the reference gene candidates selected by the three programs, the transcript level of ExoPG gene was asserted during the infection process of Ggt. There was an obvious difference between the relative expression levels normalized by the most stable reference gene and the least one. And the relative expression level of ExoPG gene was 
consistent with the results of RNA-seq (Yang et al., 2015). These results suggest that the incorrect use of reference genes may introduce bias into the analysis and lead to the misinterpretation of data.

In summary, nine candidate reference genes from $G g t$ evaluated in the infection process of Ggt using geNorm, NormFinder and BestKeeper programs, the results reveal $T U B \beta$ was the most appropriate reference gene for RT-qP$\mathrm{CR}$ normalization across the infection process of Ggt. This study constitutes the first systematic exploration in Ggt to identify optimal reference genes for RT-qPCR normalization and useful to understand the functions of candidate target genes.

\section{Acknowledgments}

The authors would like to thank Lihua Xie for her support in the RNA and DNA sample collection and performed the samples PCR. This work was supported by grants from the National Natural Science Foundation of China (31401815), The Major Project of Science and Technology in Henan Province (141100111100) and National Key Research and Development Program of China (2017YFD0201101).

\section{References}

Andersen, C. L., Jensen, J. L. and Ørntoft, T. F. 2004. Normalization of real-time quantitative reverse transcription-PCR data: a model-based variance estimation approach to identify genes suited for normalization, applied to bladder and colon cancer data sets. Cancer Res. 64:5245-5250.

Bohle, K., Jungebloud, A., Göcke, Y., Dalpiaz, A., Cordes, C., Horn, H. and Hempel, D. C. 2007. Selection of reference genes for normalisation of specific gene quantification data of Aspergillus niger. J. Biotechnol. 132:353-358.

Bustin, S. A. 2002. Quantification of mRNA using real-time reverse transcription PCR (RT-PCR): trends and problems. $J$. Mol. Endocrinol. 29:23-39.

Bustin, S. A. 2010. Why the need for qPCR publication guidelines? - The case for MIQE. Methods 50:217-226.

Bustin, S. A., Benes, V., Nolan, T. and Pfaffl, M. W. 2005. Quantitative real-time RT PCR-a perspective. J. Mol. Endocrinol. 34:597-601.

D'Ovidio, R., Mattei, B., Roberti, S. and Bellincampi, D. 2004 Polygalacturonases, polygalacturonase-inhibiting proteins and pectic oligomers in plant-pathogen interactions. Biochim. Biophys. Acta. 1696:237-244.

Fang, W. and Bidochka, M. J. 2006. Expression of genes involved in germination, conidiogenesis and pathogenesis in Metarhizium anisopliae using quantitative real-time RT-PCR. Mycol. Res. 110:1165-1171.

Gutierrez, L., Mauriat, M., Guénin, S., Pelloux, J., Lefebvre, J. F.,
Louvet, R., Rusterucci, C., Moritz, T., Guerineau, F., Bellini, C. and Van Wuytswinkel, O. 2008. The lack of a systematic validation of reference genes: a serious pitfall undervalued in reverse transcription-polymerase chain reaction (RT-PCR) analysis in plants. Plant Biotechnol. J. 6:609-618.

Hacquard, S., Veneault-Fourrey, C., Delaruelle, C., Frey, P., Martin, F. and Duplessis, S. 2011. Validation of Melampsora larici-populina reference genes for in planta RT-quantitative PCR expression profiling during time-course infection of poplar leaves. Physiol. Mol. Plant Pathol. 75:106-112.

Huang, X. L., Feng, H. and Kang, Z. S. 2012. Selection of reference genes for quantitative real-time PCR normalization in Puccinia Striiformis f.sp. tritici. J. Agric. Biotechnol. 20:181187 (in Chinese).

Kang, Z. S., Huang, L. L. and Buchenauer, H. 2000. Cytochemistry of cell wall component alteration in wheat roots infected by Gaeumannomyces graminis var. tritici. J. Plant Dis. Protect. 107:337-351.

Kim, H. K. and Yun, S. H. 2011. Evaluation of potential reference genes for quantitative RT-PCR analysis in Fusarium graminearum under different culture conditions. Plant Pathol. J. 27:301-309.

Nolan, T., Hands, R. E. and Bustin, S. A. 2006. Quantification of mRNA using real-time RT-PCR. Nat. Protoc. 1:1559-1582.

Pfaffl, M. W., Tichopad, A., Prgomet, C. and Neuvians, T. P. 2004. Determination of stable housekeeping genes, differentially regulated target genes and sample integrity: BestKeeper-Excel-based tool using pair-wise correlations. Biotechnol. Lett. 26:509-515.

Quan, X., Xue, B. G., Yang, L. R. and Wu, C. 2014. Isolation and variety identification of Gaeumannomyces graminis causing wheat take-all in Henan Province. Acta Phytopathol. Sinica 44:139-146 (in Chinese).

Radonić, A., Thulke, S., Mackay, I. M., Landt, O., Siegert, W. and Nitsche, A. 2004. Guideline to reference gene selection for quantitative real-time PCR. Biochem. Biophys. Res. Commun. 313:856-862.

Scholtz, J. J. and Visser, B. 2013. Reference gene selection for qPCR gene expression analysis of rust-infected wheat. Physiol. Mol. Plant Pathol. 81:22-25.

Schmittgen, T. D. and Zakrajsek, B. A. 2000. Effect of experimental treatment on housekeeping gene expression: validation by real-time, quantitative RT-PCR. J. Biochem. Biophys. Methods 46:69-81.

Teste, M. A., Duquenne, M., François, J. M. and Parrou, J. L. 2009. Validation of reference genes for quantitative expression analysis by real-time RT-PCR in Saccharomyces cerevisiae. BMC Mol. Biol. 10:99.

ten Have, A., Mulder, W., Visser, J. and van Kan, J. A. 1998. The endopolygalacturonase gene Bcpg1 is required for full virulence of Botrytis cinerea. Mol. Plant-Microbe Interact. 11:1009-1016.

Valette-Collet, O., Cimerman, A., Reignault, P., Levis, C. and Boccara, M. 2003. Disruption of Botrytis cinerea pectin 
methylesterase gene Bcpmel reduces virulence on several host plants. Mol. Plant-Microbe Interact. 16:360-367.

Vandesompele, J., De Preter, K., Pattyn, F., Poppe, B., Van Roy, N., De Paepe, A. and Speleman, F. 2002. Accurate normalization of real-time quantitative RT-PCR data by geometric averaging of multiple internal control genes. Genome Biol. 3:research0034.1-0034.11.

Vieira, A., Talhinhas, P., Loureiro, A., Duplessis, S., Fernandez, D., Silva Mdo, C., Paulo, O. S. and Azinheira, H. G. 2011. Validation of RT-qPCR reference genes for in planta expression studies in Hemileia vastatrix, the causal agent of coffee leaf rust. Fungal Biol. 115:891-901.
Weste, G. 1970. Extra-cellular enzyme production by various isolates of Ophiobolus graminis and O.graminis var. avenae. J. Phytopathol. 67:189-204.

Yan, H. Z. and Liou, R. F. 2006. Selection of internal control genes for real-time quantitative RT-PCR assays in the oomycete plant pathogen Phytophthora parasitica. Fungal Genet. Biol. 43:430-438.

Yang, L. R., Xie, L. H., Xue, B. G., Goodwin, P. H., Quan, X., Zhang, C. L., Liu, T. G., Lei, Z. S., Yang, X. J., Chao, Y. E. and $\mathrm{Wu}, \mathrm{C}$. 2015. Comparative transcriptome profiling of the early infection of wheat roots by Gaeumannomyces graminis var. tritici. PLoS ONE 10:e0120691. 